\title{
An interesting rare case of spontaneous pregnancy with imperforate hymen and high transverse vaginal septum with bicornuate uterus
}

\author{
Bharathi KR, Vijayalakshmi S., Divya Alamelu N.*
}

Department of Obstetrics and Gynaecology, Adichunchanagiri Institute of Medicine Science, B. G. Nagara, Karnataka571448, India

Received: 02 November 2016

Accepted: 30 November 2016

*Correspondence:

Dr. Divya Alamelu N,

E-mail: divzy_greenstarz@yahoo.co.in

Copyright: ( $\odot$ the author(s), publisher and licensee Medip Academy. This is an open-access article distributed under the terms of the Creative Commons Attribution Non-Commercial License, which permits unrestricted non-commercial use, distribution, and reproduction in any medium, provided the original work is properly cited.

\section{ABSTRACT}

Congenital anatomic disorders of the female reproductive tract may result from genetic mutation, developmental arrest and abnormal hormonal exposure during embryonic development. These anomalies have a huge impact on the woman's menstrual, sexual and reproductive functions. Pregnancy with these anatomic disorders is quite challenging. Here we present a rare interesting case of spontaneous pregnancy with multiple anatomic disorders namelyimperforate hymen, high transverse vaginal septum and bicornuate uterus.

Keywords: Bicornuate uterus, Imperforate hymen, Pregnancy, Transverse vaginal septum

\section{INTRODUCTION}

Maldevelopment of the female reproductive tract occurs in a variety of forms and each anomaly is distinctive. What appears as an apparently isolated vaginal malformation after preliminary diagnostic evaluation may be associated with uterine and other malformations. Moreover pregnancy with such kind of malformation is complicated and has to be managed with utmost caution and obstetric care. Here we present a rare case of term pregnancy diagnosed with imperforate hymen on preliminary evaluation, which later was found to be associated with high transverse vaginal septum and bicornuate uterus with left non-communicating rudimentary horn.

\section{CASE REPORT}

26 years old unbooked, Primigravida with 38 weeks of gestation came for the first visit to our hospital with complaints of low back ache since 4 days, which was dull aching and non-radiating. She had marital life of 6 years and conceived spontaneously without any evaluation for infertility. She had attained menarche at 11 years of age with regular cycles there-after for 3/30 days with scanty flow, changing one pad per day. On examination, patient had facial asymmetry with severe trismus. Her vitals were normal. Systemic examination of cardiovascular and respiratory system was normal. Obstetric examination revealed term sized uterus, which was deviated to right side, relaxed with cephalic presentation with good fetal heart rate. On examination of external genitalia, there was normal pubic hair distribution with normal urethral orifice. Hymen was imperforate. Retrospectively, patient also had complains of coital difficulty with incomplete penetration. Routine investigations were within normal limits and NST was reactive. Obstetric USG revealed single live intrauterine pregnancy of 37 weeks in cephalic presentation with adequate liquor. A tubular structure of around $9.1 * 5.2 * 3.9 \mathrm{~cm}$ was noted adjacent to the left lateral wall of uterus similar to uterine myometrial wall suggestive of duplicated left uterine horn? Didelphys uterus. Patient was prepared for Elective caesarean section in view of imperforate hymen. Intra-operatively uterus was found to be bicornuate with left rudimentary non-communicating horn. A live female baby of $2.25 \mathrm{~kg}$ was extracted. Then with the patient in lithotomy position, cruciate incision 
was made on the hymen and vaginal canal was explored. A high thin, transverse vaginal septum was noted. With guidance of finger through the uterine cavity, incision was taken on the transverse vaginal septum. After uterine and abdominal closure, patient was again put in lithotomy position and resection of transverse vaginal septum done. The edges of the septum were undermined. Postoperative period was uneventful with normal lochia.

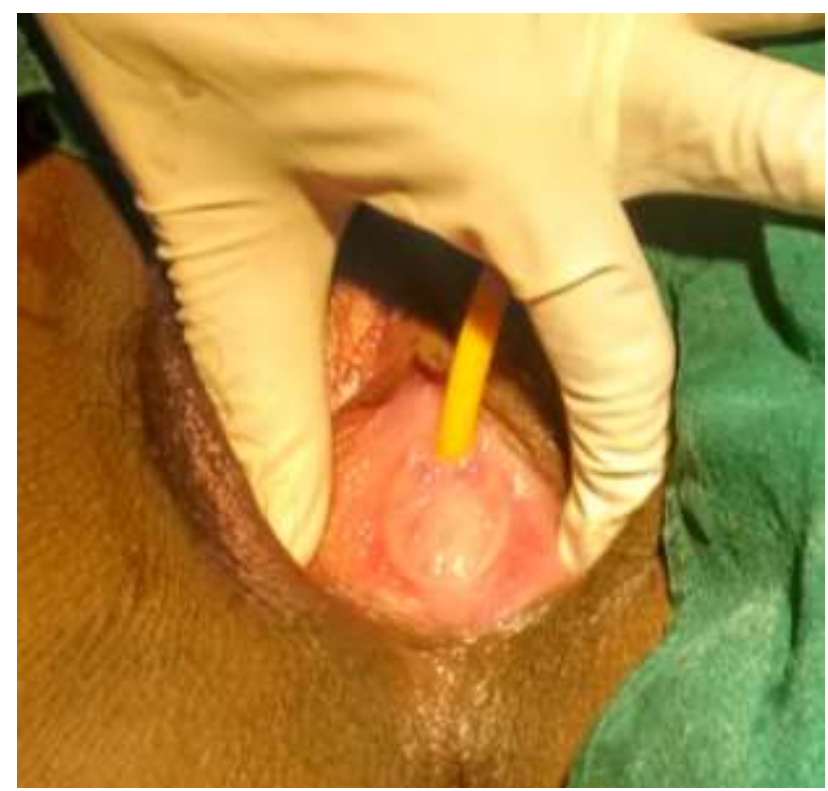

Figure 1: Imperforate hymen.

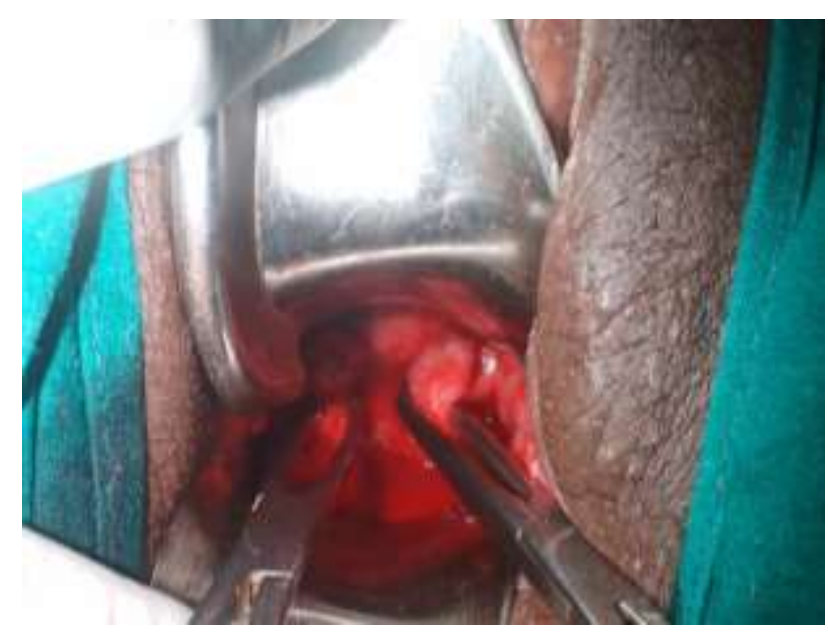

Figure 2: High transverse vaginal septum visualized after hymenotomy.

\section{DISCUSSION}

Hymen is the membranous vestige of the junction between sinovaginal bulb and urogenital sinus. It generally becomes perforate during fetal life to establish connection between the vaginal canal and perineum. Imperforate hymen follows failure of the inferior end of the vaginal plate to canalize. Incidence ranges from 1 in 1000 to 1 in 2000 . It generally presents with primary amenorrhea with hematocolpos and hematometra. In neonatal period it can manifest with hydrocolpos or mucocolpos. Incidence of imperforate hymen is reported to be $0.05-0.1 \%$.

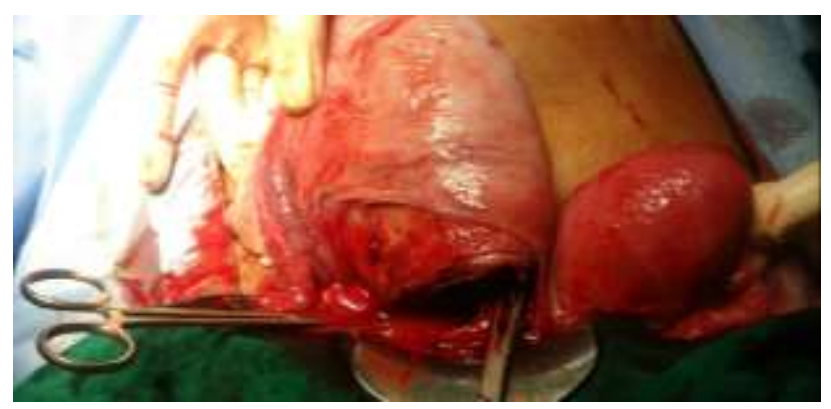

Figure 3: Bicornuate uterus with left, noncommunicating rudimentary horn.

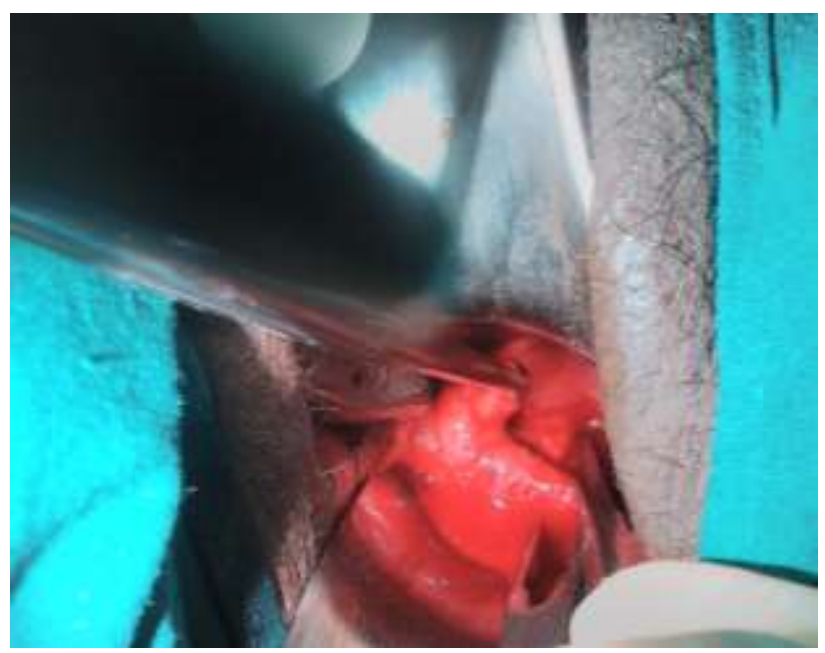

Figure 4: The edges of the septum are being held with Allis forceps.

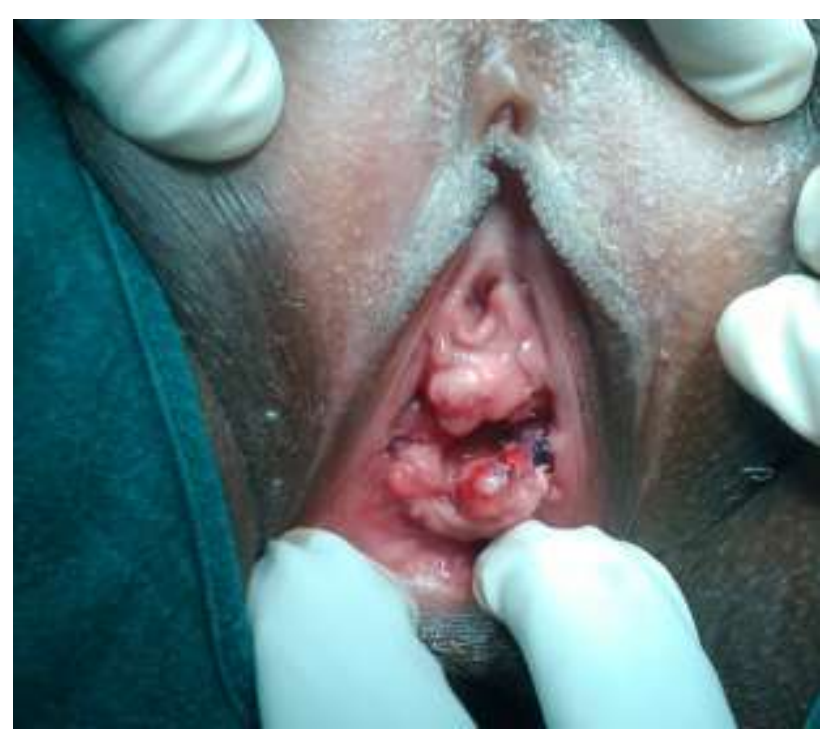

Figure 5: On post-operative day 10- The edges of the hymen. 


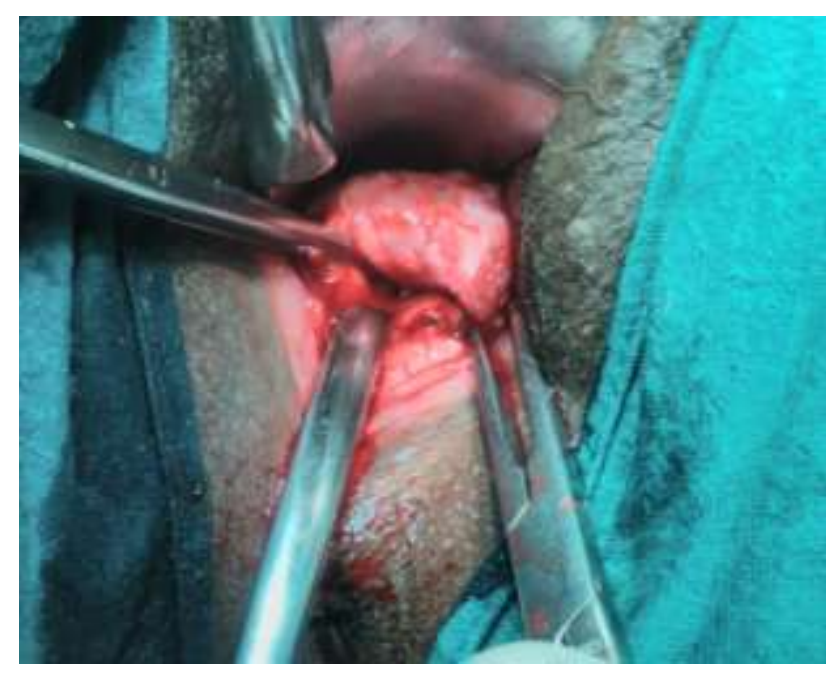

Figure 6: On post-operative day 10-The edges of the septum.

Transverse vaginal septum is due to the failure of fusion of the vaginal plate and caudal end of fused Mullerian duct. Reported incidence varies from 1 in 2,100 to 1 in 72,000 . It occurs about $46 \%$ in the upper vagina, $40 \%$ in middle vagina and $14 \%$ in lower vagina. In neonates it is associated with fluid and mucus collection in the upper vagina. In adolescents it may present with primary amenorrhea with hematometrocolpos. Pregnancy with intact and imperforate hymen is very rare and in literatures very few cases have been reported. ${ }^{1}$

Pregnancy with imperforate hymen and high transverse vaginal septum has not been reported till date. Pregnancy with imperforate hymen can be attributed to the following reasons:

- Micro perforations in the hymen or

- Spontaneous closure of hymen during pregnancy

Spontaneous closure of hymen during pregnancy has been reported in 2 cases. $^{2,3}$ Onan et al documented a case of 23 year old primigravida with 30 weeks of gestation who presented in labour, who previously had no menstrual disorders and coital difficulty. Examination revealed intact, bulging hymen. Patient underwent hyemnotomy followed by pre-term vaginal delivery. Electronic microscopy of hymenal biopsy taken revealed hymenal tissue reorganization. Onan et al had attributed the intact hymen to the spontaneous closure during pregnancy, due to the healing process. ${ }^{2,3}$ But in our case micro-perforations may be the most probable cause. Pregnancy with imperforate hymen and transverse vaginal septum may be attributed to micro perforations in both the hymen and septum. The pin-hole openings may permit normal passage of menstrual fluid and semen. Consequently spontaneous pregnancy may occur rarely.

\section{CONCLUSION}

Usually patients with imperforate hymen and transverse vaginal septum present at an early age at adolescence. Some may present at later age with primary infertility. But this is one of the rarest cases which has presented with term pregnancy without any symptoms. Proper surgical correction is essential for the long-term menstrual and reproductive welfare of the patient. Failure to manage them correctly may impact the patient's reproductive, sexual and psychological health.

\section{Funding: No funding sources \\ Conflict of interest: None declared \\ Ethical approval: Not required}

\section{REFERENCES}

1. Burgess EJ. Pregnancy with unruptured and imperforate hymen. Lancet. 1876;108(2763):237

2. Chao-Hsi L, Ching-Chung L. Hymen re-formation after hymenotomy associated with pregnancy. Aust N Z J Obstet Gynecol. 2002;42:559-60.

3. Onan MA, Turp AB, Taskiran C, Ozogul C, Himmetoglu O. Spontaneous closure of hymen during pregnancy. Am J Obstet Gynecol. 2005;193:889-91.

4. Guven D, Bakay K, Kuruoglu S. Microperforate (pinhole) hymen and infertility: A rare case report. Open J Obstet Gynecol. 2012;2:287-8

5. Goto K, Yoshinari H, Tajima K, Kotsuji F. Microperforate hymen in primigravida in active labour: A case report. J Reprod Med. 2006;51(7):584-6.

6. Shah I.A, Manhas K, Mehta N, Gupta V, Shah M. Microperforate hymen in a full term primigravida in active labour. J Med Sci. 2012;15(2):184-5.

Cite this article as: Bharathi KR, Vijayalakshmi S, Divya Alamelu N. An interesting rare case of spontaneous pregnancy with imperforate hymen and high transverse vaginal septum with bicornuate uterus. Int J Reprod Contracept Obstet Gynecol 2017;6:341-3. 